
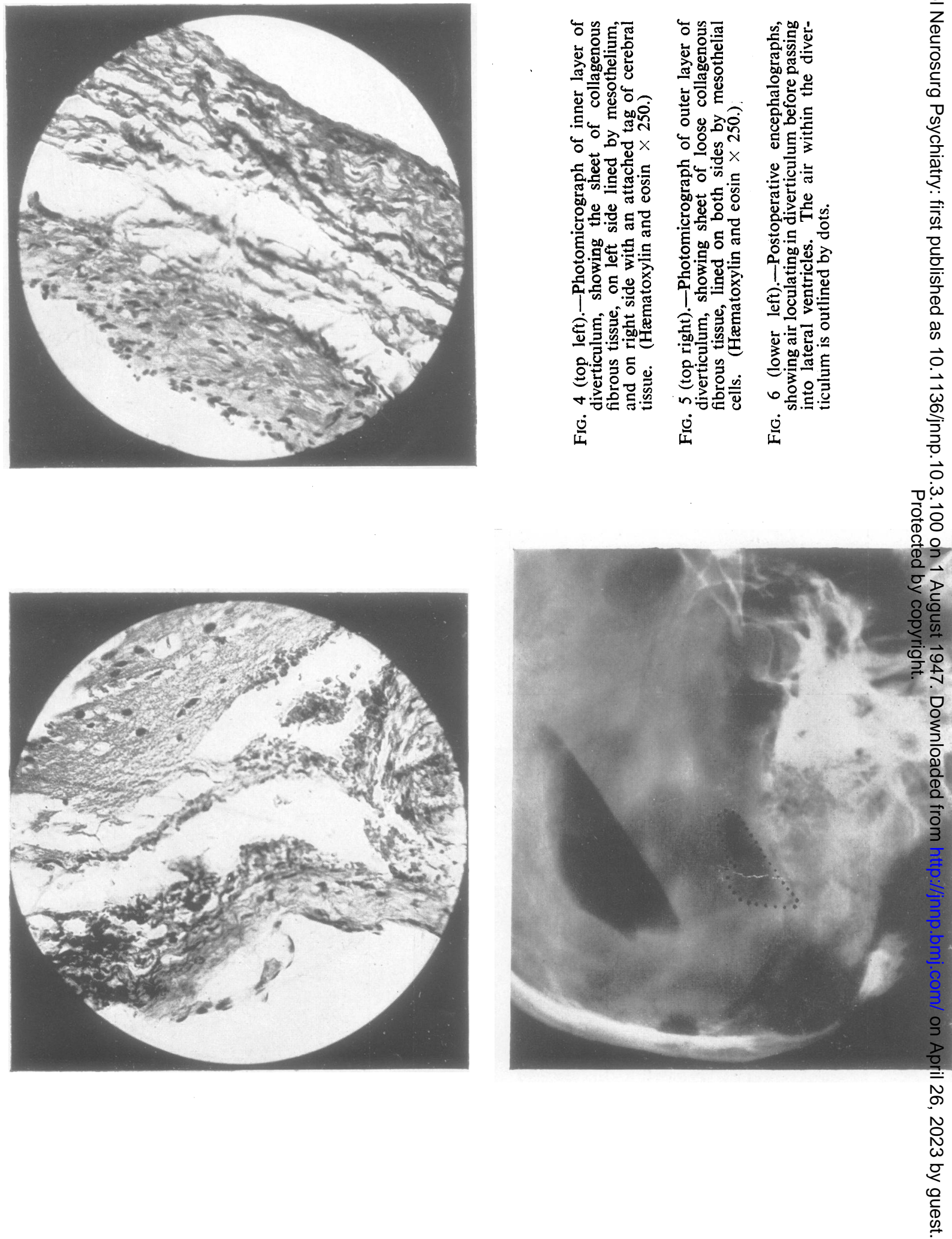


\title{
DIVERTICULUM OF THE LATERAL VENTRICLE EXTENDING INTO THE POSTERIOR CRANIAL FOSSA: REPORT OF A CASE SUCCESSFULLY RELIEVED BY OPERATION
}

\author{
BY \\ W. V. MACFARLANE and M. A. FALCONER \\ From the Department of Neurosurgery, Otago Medical School, and the Dunedin Hospital, New Zealand
}

(Received 25Th November, 1946)

OBSTRUCTIVe hydrocephalus is on rare occasions complicated by the formation of a diverticulum from one or both lateral ventricles into the posterior cranial fossa. So far six cases have been reported (Penfield, 1929 ; Sweet, 1940 ; Childe and McNaughton, 1942; Peterson, 1942 ; each one case : and Pennybacker and Russell, 1943, two cases). Pennybacker and Russell, after performing ventriculography, recognized the condition pre-operatively in one of their cases, but in this, as in the remaining recorded instances, post-mortem examination provided most of the data.

Essentially, the condition is a pulsion diverticulum of the lateral ventricle through the medial wall of the trigone. It forces its way between the crus fornicis in front, and the fibres of the splenium above and behind, where they curve posteriorly as the forceps major into the occipital lobe. It then passes through the hiatus tentorii into the posterior fossa. The first stage in development is a localized thinning of the wall of the ventricle until only the pia remains. The pial wall is then ballooned outwards into the cisterna ambiens, and as it enlarges it comes into contact with the arachnoid mater of the cistern and thrusts the arachnoid before it. The pia remains intact, preventing communication between the ventricle and the subarachnoid space.

A diversity of terminology has been used in connexion with this condition. Sweet (1940) coined the term "ventriculostium" to connote a spontaneous, as distinct from a surgical, breach in the wall of the ventricle. This term, however, considers only the orifice and ignores the pia-arachnoid pouch which is an essential feature of the condition. Pennybacker and Russell (1943) emphasized the thinning and disruption of the brain substance, and accordingly employed the term "ventricular rupture." The pia, however, has not ruptured in any of the cases so far described, and, although the cerebral substance is thinned to obliteration, no communication develops between the ventricle and the surface cerebrospinal fluid pathways, as it should if the rupture of the ventricle were complete. Childe and McNaughton (1942) chose "ventricular diverticulum " as their descriptive term, and since a "diverticulum" is defined as "a pouch leading from a main cavity " (Dorland's Medical Dictionary) this word may be suitably applied. The ventricle shows localized pouching, and this terminology is not hindered by the fact that the wall of the pouch consists of only one tunic composed of pia, while the inner and middle tunics of the ventricle, consisting of ependyma and cerebral tissue respectively, are disrupted. Indeed, the ventricular pouch is analogous to those diverticula of the alimentary tract in which the muscular layer is deficient, the mucosal layer is in part ulcerated, and only the serosal coat is intact; - and which are still called diverticula in spite of these changes. "Ventricular diverticulum," therefore, appears to us to be the most easily understood and applicable term for the condition we are describing.

The primary hydrocephalic process which precedes the formation of a diverticulum may be due to an obstruction of the aqueduct or of the third ventricle. Diverticula have been observed in association with the following conditions :

1. Astrocytoma of the brain stem, deforming or occluding the iter, was present in Pennybacker and Russell's second case, in Sweet's case, and in Peterson's.

2. Benign gliotic stricture of the aqueduct was found in Pennybacker and Russell's first case, and is presumed to be the cause in our own.

3. Cholesteatoma of the third ventricle, with occlusion of the foramen of Munro, was present in Penfield's case.

4. Polar spongioblastoma of the hypothalamic region, filling the third ventricle and blocking the aqueductal orifice, was the primary pathological condition in Childe and McNaughton's case. 
Childe and McNaughton (1942) consider that, in addition to the increase of pressure and consequent dilatation which occur in the lateral ventricles in these various pathological conditions, another factor is also necessary for the production of one of these diverticula. This is the absence of any large space-occupying lesion in the cerebellar region which might resist the entrance of the cyst through the hiatus tentorii. This latter feature probably accounts for the rarity of these protrusions into the posterior cranial fossa.

In most cases these diverticula are apparently symptomless. This doubtless explains why, in those cases in which a tumour has been the underlying cause and which have been submitted to operation, the surgical attack has usually been directed towards the tumour. Yet theoretically if the pial wall of the cyst were to rupture, either spontaneously or as a result of operation, a ventriculostomy would be produced which would short-circuit the obstructing lesion. However, Pennybacker and Russell's two cases are the only ones recorded in which the diverticulum has been approached at operation. A cerebellar exposure was used, and in both cases the diverticulum was incised and opened into the subdural space. Both cases, however, succumbed : one on the ninth postoperative day, following two Jacksonian epileptic attacks; and one shortly after operation, from an extradural hæmorrhage compressing the right cerebral hemisphere.

The present report concerns the successful surgical treatment of a diverticulum of the lateral ventricle by the establishment of a lateral ventriculostomy into the cisterna ambiens. It draws attention again to the fact that the wall of the diverticulum, as exposed surgically, consists of two layers, one of pia and one of arachnoid, between which is the collapsed subarachnoid space.

\section{Case History}

A man, aged twenty-three years, was referred by Dr. I. M. Allen of Wellington, and was admitted to this Unit on Sept. 14, 1945. He had been an apparently normal child until the age of five years, when daily frontal headaches had begun and had continued for ten years. At roughly three-monthly intervals he had suffered attacks of somnolence lasting for periods of two or three weeks, and in his seventh year these were diagnosed as encephalitis lethargica. When he left school, at the age of fifteen, he was three years below the normal attainment. He then developed attacks of vomiting associated with headache on waking each morning, and he also showed ataxia of the arms and reduced powers of concentration. Examination revealed low-grade papillœdema of both optic discs, and the radiographs of the skull showed increased convolutional markings. A cerebellar tumour was diagnosed, and the posterior fossa was explored by
Mr. H. K. Corkill through a mid-line vertical incision. The reported positive findings were a thickening of the arachnoid mater and a dilatation of the cisterna magna. An operative diagnosis of arachnoiditis circumscripta cisternalis was made, and a cerebellar decompression of was provided.

For the next seven years he was relieved of symptoms, and during that time he passed through his apprenticeship of as a cabinet maker. Then, one year before his admission to hospital, he suffered a relapse with an initial two weeks' bout of projectile vomiting and neck stiffness. This was associated each day with violent frontal headaches which continued without remission. Co-ordination of his $\overrightarrow{\vec{F}}$ hands for writing and cigarette rolling decreased during the last six months. Finally his legs became ataxic and his speech dysarthric, and he was increasingly sleepy.

On admission he was found to be a heavy-looking $\frac{\bar{s}}{D}$ youth with a large head (maximum circumference $59 \mathrm{~cm}$.) and thin, hypotonic limbs. His alertness varied from sleepiness to mild euphoria. His recent memory and concentration were defective, but he made pungent $\vec{O}$ criticisms of his medical examiners. He took eight minutes to subtract serial sevens from one hundred, $\vec{\omega}$ making seven mistakes in the process, and he could only? recall five digits in the digit-retention test. It is of interest that after his recovery he could not recall his? admission to hospital nor his transfer by air ambulance. $\vec{O}$ Examination disclosed bilateral papillœdema of $1+\omega$ without hæmorrhages. The right pupil was slighty $\vec{\circ}$ larger than the left. There was no nystagmus. Slight weakness of movement of the right side of the face wo을 detected. The limbs showed ataxia and hypotonfa more marked on the right than on the left side. Clon is was present in the right ankle, but the tendon jerks wegeco not exaggerated; the plantar responses were flexe्ष. He could not sit up unaided, and he walked with pronounced zig-zag stagger. Lumbar puncture severif weeks earlier had provided a clear cerebrospinal flưid. (white cells, 10 per c.mm. ; protein, $35 \mathrm{mg}$. per $100 \mathrm{ml}$.) under a pressure of $280 \mathrm{~mm}$. of cerebrospinal fluid.

The provisional diagnosis, entertained on clinical grounds, was of mid-line cerebellar tumour which hado lain latent for seven years under the influence of a응 decompression, but which had now expanded to the point of decompensation.

VENTRICULOGRAPHY.-On the day after admission $\frac{0}{3}$ ventriculography was carried out through bilateral $\vec{J}$ parietal burr holes made under local anæsthesia. Both lateral ventricles were tapped at $3 \mathrm{~cm}$. depth. The intraventricular pressure was found to be $150 \mathrm{~mm}$. of cerebrospinal fluid. Air-filling of the ventricles was? carried out from both sides, $300 \mathrm{ml}$. of cerebrospinalo fluid being obtained. The six standard Lysholm projections were used in the $x$-ray examination (Figs. 1 and $\delta$ 2). Both lateral ventricles and the third ventricle were 3 shown to be greatly dilated. The third ventricle filled 0 well, but the upper end of the aqueduct filled only for $6 \mathrm{~mm}$. and no air passed below that point. The appear $-\frac{D}{2}$ ances suggested a benign stricture of the aqueduct. $A \cong$. large air-containing cyst was observed behind the third ventricle and below the tentorium cerebelli. It measured ${ }^{\text {S }}$ $6.7 \mathrm{~cm}$. wide, by $5.2 \mathrm{~cm}$. high, by $4.9 \mathrm{~cm}$. from before $\mathrm{N}$ 

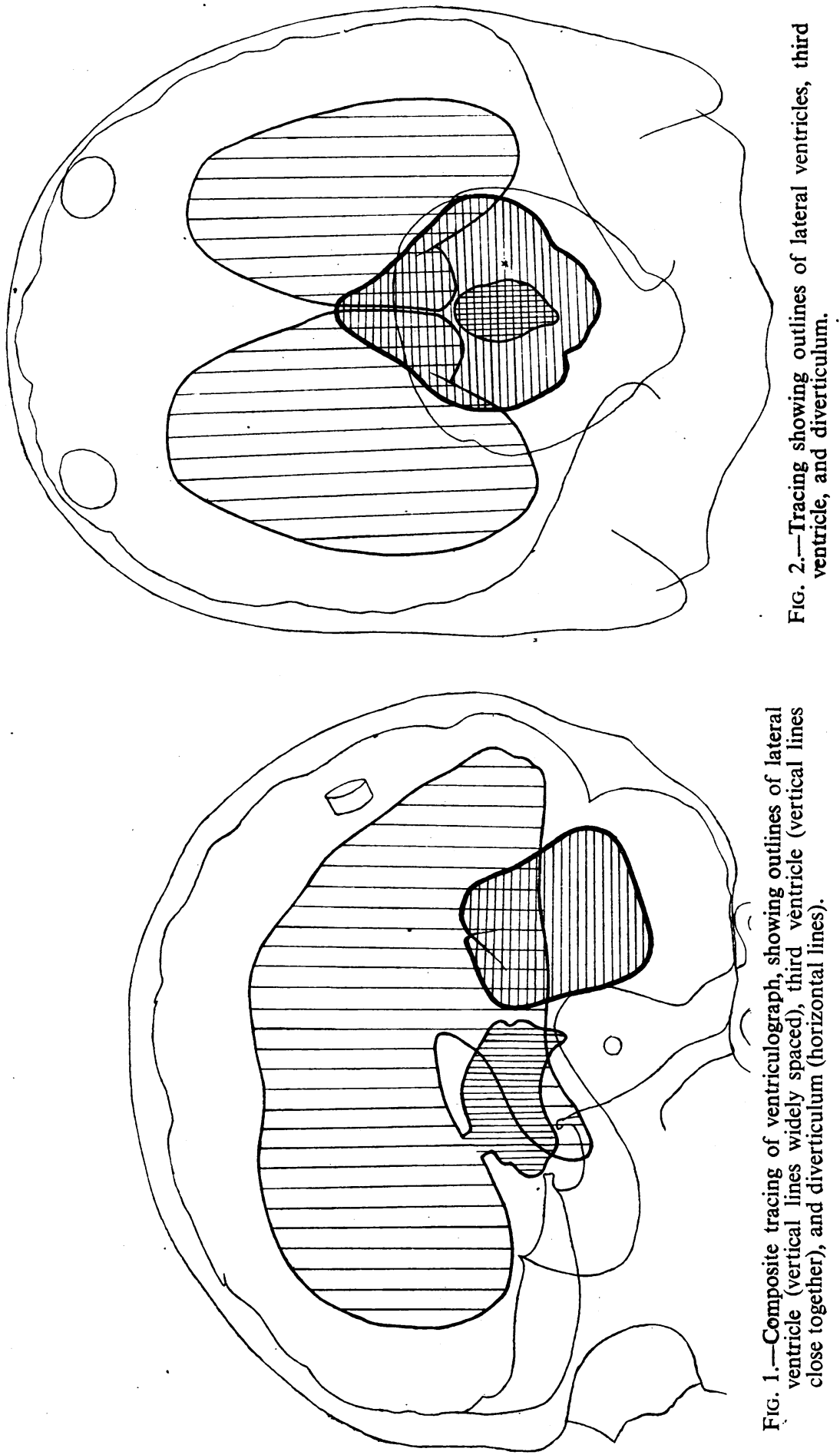

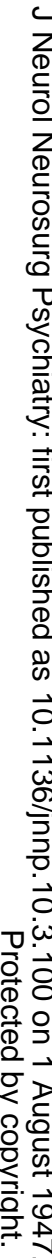

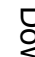

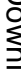

के

ํำ

옥

륨

产

흥

홍

옳

9

을

N

N

స్లు

इ

음 


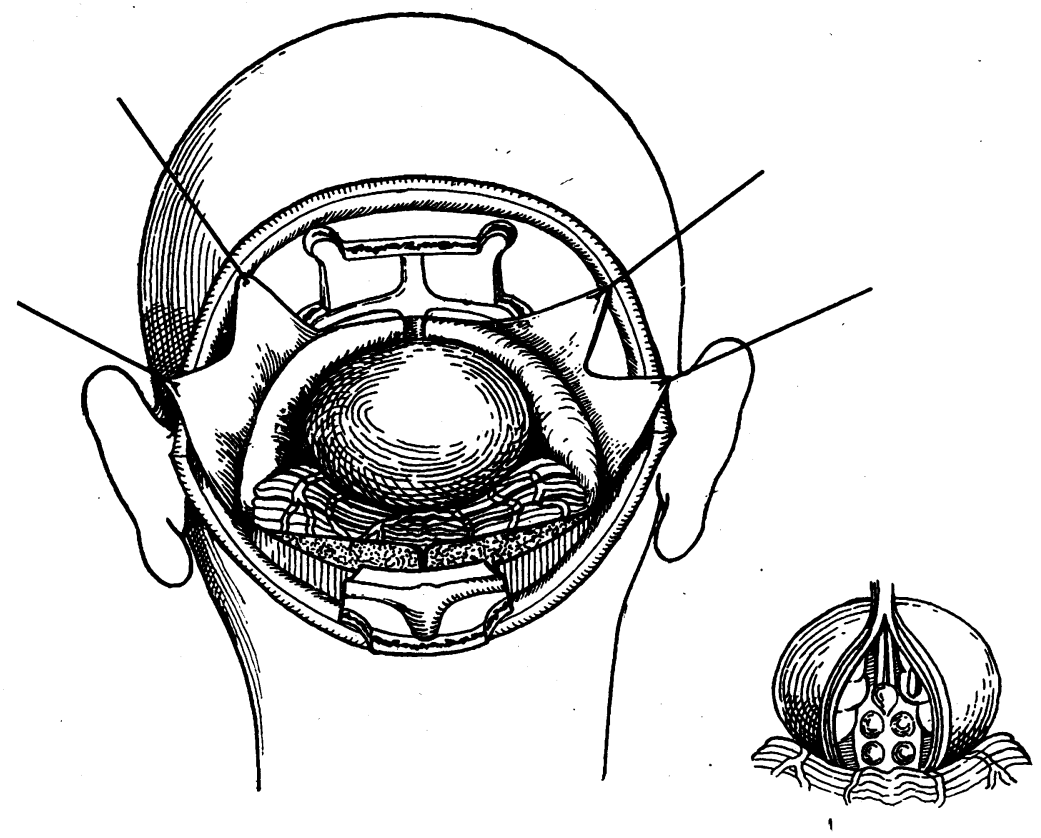

backwards. From the lateral aspect it was rhomboidal (Fig. 1). In the oblique postero-anterior projection the cyst was pear-shaped with the base inferiorly (Fig. 2). Integration of all views into three dimensions indicated a tent-like structure, with a concave floor and with a projection of the roof upwards and forwards between the vestibules of the lateral ventricles. The appearances were recognized as similar to those reported for diverticula by Pennybacket and Russell (1943).

OPERATION.-Immediately after ventriculography an operation was performed by one of us (M.A.F.) under intratracheal nitrous oxide, ether, and oxygen anæsthesia. A curved transverse scalp incision was made just above the level of the superior curved line of the occipital bone. A small bone flap covering the torcula Herophili and the proximal $2 \mathrm{~cm}$. of each lateral sinus was turned downwards with the suboccipital muscles attached to it. The original decompression was clearly not functioning, since a thin widespread film of new bone had formed. This bone was removed. Although the exposed cerebellum seemed full, no tumour showed on its surface. The upper right sector of the cerebellum was then explored with a brain needle, and in the process a puff of air escaped. Immediately the cerebellar hemispheres collapsed, and when they were then retracted downwards a bluish white cyst was exposed, and incised (Fig. 3). The cyst lay between the tentorium cerebelli posterosuperiorly, the veins of Galen and the occipital lobes antero-superiorly, and the vermis and cerebellar hemispheres inferiorly; the pineal body, corpora quadrigemina, and mesencephalon bordered it anteriorly. It protruded upward through the dilated hiatus tentorii, which measured $3 \mathrm{~cm}$. by $2.5 \mathrm{~cm}$. exclusive of the portion taken up by the brain stem, to a vertical opening, $1.2 \mathrm{~cm}$. high by $0.5 \mathrm{~cm}$. wide, in the medial wall of the right hemisphere. Through this opening it communicated with the right lateral ventricle (inset, Fig. 3).

When incised the posterior wall of the cyst was found to consist of two closely apposed layers of thin membranous tissue, which were readily separated. The inner layer was attached to the margins of the ventricular stoma, while the outer was continuous with the arachnoid mater of the cisterna ambiens. 'The inner layer was then stripped off and cut away from the outer layer on either side, in the lateral angle between cerebellum and tentorium, so opening up the subarachnoid space of the cisterna ambiens. In this, way a communication between the right lateral ventricle and the cisterna ambiens was attempted.

Pathology.-Specimens of both layers of the diverticulum were examined histologically. The inner membrane was made up of a thin wavy sheet of collagenous fibrous tissue between 70 and $80 \mu$ wide. Its inner surface showed no well-defined boundary to the connective tissue, but had tags of cerebral white matter, up to 80 by $30 \mu$ in size, adherent to it (Fig. 4, p. 100). Its 
outer surface was lined with mesothelium composed of one or two layers of large cells with slightly fiattened nuclei and scanty cytoplasm. These mesothelial cells presumably faced the subarachnoid space. The appearances of this membrane were consistent with its being pia mater to which portions of brain tissue were adherent.

The outer membrane was three times thicker than the inner (Fig. 5, p. 100). It was lined on both surfaces by flattened mesothelial cells similar to those seen on the pia externally. Between the two mesothelial layers were fasciculi of fibrous tissue interspersed with isolated mesodermal cells. This membrane had the appearance of arachnoid mater.

Postoperative Course.-Convalescence was at first stormy, and patient remained drowsy and disorientated for five days. Respirations were slow and periodic for four days. A coarse nystagmus was present on the patient's looking to the left side, but not when he looked to the right. The left limbs were temporarily weaker than before operation, and the ataxia was increased in all limbs. Lumbar puncture pressures rose as high as $450 \mathrm{~mm}$. of cerebrospinal fluid during the first four days. By the end of one month he had recovered from the ataxia, the texture of his voice had become lighter and less slurred, and his mental processes were more alert.

Tests for patency of the ventriculostomy were carried out two months after operation. Neutral phenolsulphonephthalein ( $2 \mathrm{ml}$. of 6 per cent. solution) was injected into the right lateral ventricle. After thirty minutes a lumbar puncture was performed with the patient sitting, and as the cerebrospinal fluid dripped away it was replaced by air. The dye did not appear until $60 \mathrm{ml}$. of fluid had been withdrawn. Radiographs taken during the procedure showed that the air loculated under the tentorium cerebelli in a space above the cerebellum formerly occupied by the diverticulum, and then passed into the right lateral ventricle and thence to the left (Fig. 6, p. 100). Some air entered the fourth ventricle, but none was detected in the third ventricle. It therefore appeared that the stoma between the lateral ventricle and the cisterna ambiens was patent and functioning. Incidentally the fourth ventricle was in its normal situation, and a correlation of this finding with the outlines of the third ventricle seen in the original ventriculograms, when only the upper end of the aqueduct filled, affords strong corroborative evidence of a gliotic stricture of the aqueduct.

The patient returned home ten weeks after operation. He felt fit, wrote and walked well, and was free of headaches. There was a residual trace of papillœdema, and a flicker of nystagmus. His mental age when tested by Raven's matrices was nine years, his intelligence quotient being 75 (Binet scale).

Follow UP.-He was last seen at the end of a year. Throughout that time he had remained free from symptoms of raised intracranial pressure, and had performed odd jobs, helping his father in his workshop. It took some time to restore his confidence, and it was not until eleven months after operation that he returned to his former occupation of cabinet maker. He then appeared to be progressing satisfactorily. Examination showed normal visual acuity and no papillœdema or nystagmus, but there was slight ataxia of the left arm and left leg. His intelligence quotient as tested by the Raven matrices was 78 (Binet scale).

\section{Discussion}

Several noteworthy points arise from observations made in this case. The first is that diverticula may be expected in certain cases of advanced hydrocephalus, and can be detected preoperatively only by ventriculography. This reinforces the argument for routine ventriculography before craniotomy in all but the most clear-cut intracranial problems. In the earlier reported cases the ventriculographic appearances were often misinterpreted. Penfield (1929) diagnosed a supratentorial pouch; Childe and McNaughton (1942) regarded the shadow as that of the fourth ventricle displaced upwards by tumour; Peterson (1942) considered it to be a cystic tumour ; and Pennybacker and Russell (1943) in their first case considered the appearance to be that of a dilated suprapineal recess of the third ventricle. Subsequently in their second case Pennybacker and Russell interpreted the diverticular shadow correctly. If the existence of these diverticula be kept in mind, the ventriculographic diagnosis is straightforward. Typically, the shadow in the lateral view lies level with the dorsum sellæ, and behind the posterior end of the third ventricle. It is separated from the dorsum sellæ by the thickness of the mid-brain. In the postero-anterior view the diverticulum is superimposed on the third ventricle and extends upward between the lateral ventricles.

The second point is that the cyst is composed of two layers, one of pia and one of arachnoid, between which lies the collapsed subarachinoid space. Sweet (1940), Childe and McNaughton (1942), and Pennybacker and Russell (1943) all noted this but did not emphasize its operative importance. We believe that merely incising the fundus of the diverticulum during the course of a cerebellar approach, and so opening the diverticulum into the subdural space, is not sufficient to provide a functioning ventriculostomy, as the two membranes comprising the diverticulum may remain in contact. The essential part of the operation is the separation of the inner pial membrane from the arachnoid, especially in the angles between cerebellum and tentorium close to the mid-brain, thus opening up the cisterna ambiens. 'In our patient postoperative tests with dye and encephalography demonstrated clearly that a lateral ventriculostomy produced in this way can function efficiently.

The operation of lateral ventriculostomy, as performed in our patient, has probably two factors which favour its success. One of these, the shortcircuiting of the flow of cerebrospinal fluid, has just 
been considered. The other, the provision of a cerebellar decompression; may of itself be adequate in a proportion of cases. We have had experience of a case of benign gliotic stricture of the aqueduct, proven at autopsy, in which symptoms had been relieved for ten years by a cerebellar decompression. The mechanism by which this relief was brought about is difficult to understand, but other surgeons (Pennybacker, 1940) have had similar experiences.

The favourable outcome of lateral ventriculostomy in our patient suggests to us that this is the operative procedure of choice when a diverticulum of this type is disclosed by ventriculography. In cases where neoplasm has been the cause, the neoplasm has always been deep-seated, and the operative attack upon it has so far always failed. A combination of cerebellar decompression and lateral ventriculostomy, followed later by deep $x$-ray therapy, might have benefited some of the recorded cases, at least temporarily. Pennybacker and Russell have advised that when gliotic stricture of the aqueduct is the cause, an anterior third ventriculostomy should be tried in the first instance. This latter procedure, however, fails to function successfully in an appreciable proportion of cases, and, moreover, it is not accompanied by the added benefit of a cerebellar decompression.

\section{Summary}

1. A case of presumed gliotic stricture of the aqueduct, associated with resulting hydrocephalus and the formation of a diverticulum of the right lateral ventricle, is described. The diverticulum presented between the tentorium above and the cerebellum below, and was visualized by ventriculography.

2. At operation the diverticulum was found to be lined by two layers, one of pia mater and one of arachnoid mater. A communication between the lateral ventricle and the cisterna ambiens was established by separating the two layers and removing the inner layer.

3. Importance is attached to the two layers of the cyst and to the effectiveness of the lateral ventriculostomy resulting from their separation. It is likely that the cerebellar decompression performed during this operation is also of therapeutic value.

We wish to thank Dr. E. D'Ath for advice on biopsy specimens, Dr: A. C. Begg for the ventriculographs, and Mr. H. K. Corkill, F.R.C.S., for his notes on the first cerebellar exploration.

\section{REFERENCES}

Childe, A. E., and McNaughton, F. L. (1942). Arch. Neurol. Psychiat., Chicago, 47, 768.

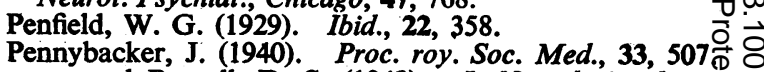
6, and Russell, D. S. (1943). J. Neurol. Psychiat. 융 읭

Peterson, H. O. (1942). Communication to Childe and McNaughton (op. cit.).

Sweet, W. H. (1940). Arch. Neurol. Psychiat., Chicago 44, 532 . 